\title{
Normal bacterial flora may inhibit Candida albicans biofilm formation by Autoinducer-2
}

\author{
Robert J. C. McLean* \\ Department of Biology, Texas State University, San Marcos, TX, USA \\ ${ }^{*}$ Correspondence: mclean@txstate.edu \\ Edited by: \\ Chad J. Roy, Tulane University, USA \\ Reviewed by: \\ Michael L. Vasil, University of Colorado School of Medicine, USA \\ Balasubramanian Natesan, New University of Lisbon, Portugal
}

Keywords: Autoinducer-2, Interkingdom signaling, biofilm inhibition, Quorum Sensing, Candidiasis

\section{A commentary on}

AI-2 of Aggregatibacter actinomycetemcomitans inhibits Candida albicans biofilm formation

by Bachtiar, E. W., Bachtiar, B. M., Jarosz, L. M., Amir, L. R., Sunarto, H., Ganin, H., et al. (2014). Front. Cell. Infect. Microbiol. 4:94. doi: 10.3389/fcimb.2014.00094

Bachtiar et al. (2014) present a very interesting study in which they illustrate the ability of AI-2, produced by Aggregatibacter actinomycetemcomitans to inhibit biofilm formation by the fungal opportunistic pathogen Candida albicans. C. albicans is considered to be the most common fungal pathogen of humans, manifesting itself in the oral cavity (oral candidiasis or thrush), female reproductive tract (commonly referred to as a yeast infection), and less commonly in the digestive tract. It is also a notable bloodborne nosocomial pathogen (reviewed in Moyes and Naglik, 2011). While candidiasis is a complication in immunocompromised patients (Moyes and Naglik, 2011; Gow and Hube, 2012), in most other situations candidiasis arises as a consequence of normal flora disruption (Gow and Hube, 2012).

In contrast to the considerable work done on mucosal immunity and other aspects of the immune system, less work has been done on mechanisms whereby normal flora control C. albicans. As part of its virulence, $C$. albicans does form biofilms through a quorum-regulated developmental process analogous to bacterial biofilms (Chandra et al., 2001; Ramage et al., 2002). Hogan and Kolter
(2002) showed that Pseudomonas aeruginosa biofilms could colonize and inhibit C. albicans only when C. elegans was growing in the mycelia form and not the yeast form. These authors found that $P$. aeruginosa production of type 4 pili, involved in biofilm formation, antimicrobial phenazines, and other virulence factors, notably phospholipase C, were important inhibitors of C. albicans (Hogan and Kolter, 2002). Cruz et al. illustrated how proteins produced by Enterococcus faecalis could inhibit C. albicans hyphal growth and virulence (Cruz et al., 2013). There have also been reports of other specific interactions between individual bacteria and Candida albicans (reviewed in Shirtliff et al., 2009). While these studies address specific mechanisms, relevant to a specific bacterial species' interaction with C. albicans, it does not address the general phenomenon of normal flora inhibition of C. albicans growth and virulence. In this context, the study by Bachtiar et al. (2014), represents an intriguing and very welcome development.

Autoinducer 2 (AI-2), encoded by $\operatorname{luxS}$ has been likened to a universal quorum signal in that it is produced and responded to by a wide number of bacterial species ( $\mathrm{Ng}$ and Bassler, 2009). In their study, Bachtiar et al. (2014) focused on the interaction of $A$. actinomycetemcomitans with $C$. albicans. Using genetically defined strains, they showed that luxS mutants were unable to inhibit biofilm formation in $C$. albicans, but that this inhibition could be restored by genetic complementation or through the addition of physiologically-relevant concentrations of synthetic AI-2 or spent media from
AI-2-producing A. actinomycetemcomitans. Although $A$. actinomycetemcomitans, found in the sub-gingival crevice, is normally a minor component of the oral cavity (Ramsey and Whiteley, 2009), the universal presence of AI-2 in many bacteria ( $\mathrm{Ng}$ and Bassler, 2009) suggests that this signal molecule may represent a heretofore unrecognized general mechanism of the normal flora that protect against $C$. albicans infections. Certainly, work is needed with other AI-2-producing members of the normal flora to confirm this possibility. In light of the work by Hogan and Kolter (2002), it would also be very appropriate to determine whether AI-2 inhibition of $C$. albicans was a general phenomenon rather than being restricted to a specific physiological state (i.e., mycelia or yeast growth) of this fungal opportunistic pathogen.

In summary, while there is considerable interest in exploiting quorum signal disruption as an antimicrobial therapy (Christensen et al., 2012; Vega et al., 2014), the work of Bachtiar et al. (2014) implies that enhanced $C$. albicans virulence might be an undesired consequence of this quorum-inhibiting strategy, as is the case with antibiotic-induced normal flora reduction (Gow and Hube, 2012).

\section{REFERENCES}

Bachtiar, E. W., Bachtiar, B. M., Jarosz, L. M., Amir, L. R., Sunarto, H., Ganin, H., et al. (2014). AI-2 of Aggregatibacter actinomycetemcomitans inhibits Candida albicans biofilm formation. Front. Cell. Infect. Microbiol. 4:94. doi: 10.3389/fcimb.2014.00094

Chandra, J., Kuhn, D. M., Mukherjee, P. K., Hoyer, L. L., McCormick, T., and Ghannoum, M. A (2001). Biofilm formation by the fungal pathogen 
Candida albicans: development, architecture, and drug resistance. J. Bacteriol. 183, 5385-5394. doi: 10.1128/JB.183.18.5385-5394.2001

Christensen, L. D., van Gennip, M., Jakobsen, T. H., Alhede, M., Hougen, H. P., Hoiby, N., et al. (2012). Synergistic antibacterial efficacy of early combination treatment with tobramycin and quorum-sensing inhibitors against Pseudomonas aeruginosa in an intraperitoneal foreignbody infection mouse model. J. Antimicrob. Chemother. 67, 1198-1206. doi: 10.1093/jac/ dks002

Cruz, M. R., Graham, C. E., Gagliano, B. C., Lorenz, M. C., and Garsin, D. A. (2013). Enterococcus faecalis inhibits hyphal morphogenesis and virulence of Candida albicans. Infect. Immun. 81, 189-200. doi: 10.1128/IAI.00914-12

Gow, N. A., and Hube, B. (2012). Importance of the Candida albicans cell wall during commensalism and infection. Curr. Opin. Microbiol. 15, 406-412. doi: 10.1016/j.mib.2012.04.005

Hogan, D. A., and Kolter, R. (2002). PseudomonasCandida interactions: an ecological role for virulence factors. Science 296, 2229-2232. doi: $10.1126 /$ science. 1070784
Moyes, D. L., and Naglik, J. R. (2011). Mucosal immunity and Candida albicans infection. Clin. Dev. Immunol. 2011:346307. doi: 10.1155/2011/ 346307

Ng, W. L., and Bassler, B. L. (2009). Bacterial quorumsensing network architectures. Annu. Rev. Genet. 43, 197-222. doi: 10.1146/annurev-genet-102108134304

Ramage, G., Saville, S. P., Wickes, B. L., and LópezRibot, J. L. (2002). Inhibition of Candida albicans biofilm formation by farnesol, a quorum-sensing molecule. Appl. Environ. Microbiol. 68, 5459-5463. doi: 10.1128/AEM.68.11.5459-5463.2002

Ramsey, M. M., and Whiteley, M. (2009). Polymicrobial interactions stimulate resistance to host innate immunity through metabolite perception. Proc. Natl. Acad. Sci. U.S.A. 106, 1578-1583. doi: 10.1073/pnas.0809533106

Shirtliff, M. E., Peters, B. M., and Jabra-Rizk, M. A. (2009). Cross-kingdom interactions: Candida albicans and bacteria. FEMS Microbiol. Rev. 299, 1-8. doi: 10.1111/j.1574-6968.2009.01668.x

Vega, L. M., Alvarez, P. J., and McLean, R. J. C. (2014). Bacterial signaling ecology and potential applications during aquatic biofilm construction.
Microb. Ecol. 68, 24-34. doi: 10.1007/s00248-0130321-1

Conflict of Interest Statement: The author declares that the research was conducted in the absence of any commercial or financial relationships that could be construed as a potential conflict of interest.

Received: 30 June 2014; accepted: 11 August 2014; published online: 28 August 2014.

Citation: McLean RJC (2014) Normal bacterial flora may inhibit Candida albicans biofilm formation by Autoinducer-2. Front. Cell. Infect. Microbiol. 4:117. doi: $10.3389 /$ fcimb. 2014.00117

This article was submitted to the journal Frontiers in Cellular and Infection Microbiology.

Copyright (C) 2014 McLean. This is an open-access article distributed under the terms of the Creative Commons Attribution License (CC BY). The use, distribution or reproduction in other forums is permitted, provided the original author(s) or licensor are credited and that the original publication in this journal is cited, in accordance with accepted academic practice. No use, distribution or reproduction is permitted which does not comply with these terms. 